\title{
Comparison of mean shear wave velocity of the top 30 m using downhole, MASW and bender elements methods
}

\author{
Comparación del promedio de la velocidad de onda de corte en los primeros 30 m usando \\ ensayos downhole, MASW y bender elements
}

Fecha de entrega: 5 de mayo 2016 Fecha de aceptación: 16 de septiembre 2016

\section{Ricardo Moffat ${ }^{1}$, Nicolle Correia ${ }^{2}$ and Cesar Pastén ${ }^{2}$}

\author{
${ }^{1}$ Faculty of Engineering and Sciences, Universidad Adolfo Ibáñez, Diagonal Las Torres 2640, edificio D, Peñalolen, Santiago, Chile, \\ ricardo.moffat@uai.cl \\ ${ }^{2}$ Department of Civil Engineering, University of Chile, Blanco Encalada 2002, Santiago, Chile, nicolle.correia@gmail.com, \\ cpasten@ing.uchile.cl
}

Multichannel Analysis of Surface Waves MASW tests were performed in different seismic stations where boring information and downhole tests were available. Active MASW tests were performed using 12 geophones of 4.5 $\mathrm{Hz}$ of frequency repeating 5 tests in each location. From the readings, dispersion curves were obtained using a $f-k$ analysis with the software Geopsy. The shear wave velocity $V_{S}$ profiles were obtained by inverting the deduced dispersion curves. Downhole tests were analyzed using the direct approach in four stations (Maipú, Peñalolen, Casablanca and Melipilla), and using existing Vs results for Llolleo site. $V_{S}$ profiles obtained from MASW and downhole tests are compared and the average shear wave velocity of the top $30 \mathrm{~m}\left(V_{S 30}\right)$ calculated for each station. $V_{S}$ profiles obtained from downhole and MASW active tests are similar up to $30 \mathrm{~m}$. Therefore, a good testing methodology and analysis of the MASW data allows reliable results and the same seismic classification of the soil. The major differences were found where there is a large impedance of two layers of soils such as it was found in Melipilla site.

Keywords: shear wave velocity, MASW, downhole, seismic classification

\section{Introduction}

Non-invasive geophysical methods have been used to estimate the shear wave velocities of soil layers in order to interpret physical properties such as stiffness and liquefaction potential of the soil. Applications using the surface waves started in the fifties with the geophysical method Steady State Rayleigh SSRM. In particular, surface wave methods (using active or passive source) have been applied since the 1980s (Nazarian and Stokoe, 1986) and
Ensayos geofisicos MASW (Multichannel Analysis of Surface Waves) son ejecutados en diferentes estaciones sísmicas donde existe información de estratigrafía de sondajes y ensayos del tipo downhole. Ensayos activos MASW se ejecutaron usando 12 geófonos de $4.5 \mathrm{~Hz}$ de frecuencia repitiendo 5 ensayos en cada ubicación. Se obtienen las curvas de dispersión usando un análisis $f-k$ con el software Geopsy. El perfil de velocidad de onda de corte $V_{S}$ se obtiene de la inversión de dichas curvas de dispersión. Los resultados de ensayos downhole son analizados mediante el método directo en cuatro estaciones (Maipú, Peñalolén, Casablanca y Melipilla), además se usan datos mostrados en estudios anteriores para el sitio de Llolleo. Los perfiles de $V_{S}$ obtenidos de ensayos MASW $y$ downhole son similares hasta los $30 \mathrm{~m}$ de profundidad. Por lo tanto mediante un ensayo y metodología de análisis adecuados de MASW se puede obtener resultados adecuados de perfiles $V_{S}$ y la misma clasificación sísmica del suelo que con el ensayo downhole. La mayor diferencia se observan en sitios donde existe una gran impedancia de dos capas de suelo tal como se observó en Melipilla.

Palabras clave: velocidad de onda de corte, MASW, downhole, clasificación sísmica

still being broadly used nowadays (Everett, 2013). In the eighties, the Spectral Analysis of Surface Waves SASW was introduced to obtain the $V_{\mathrm{S}}$ profile of the subsoil. Multistation approach become widespread in the late 1990s and today MASW (Multiple Analysis of Surface Waves) is the most used approach.

It is important to notice that seismic waves travel through rock and soil following paths that depend on the density, 
stiffness, and stratification of soils. Waves that pass through these materials are compressive waves $\mathrm{P}$ and shear waves S. P-waves can travel through any material that supports compressional forces (solids and liquids) whereas S-waves can only travel through materials that have shear strength therefore they are not transfer in liquids or gases. Soils $\mathrm{P}$ - and S-wave velocities, $V_{\mathrm{P}}$ and $V_{\mathrm{S}}$, respectively, depend mainly of the type of soil, their stiffness and density.

Additionally, on the soil surface there are other types of waves; Love and Rayleigh waves. These waves travel along the surface with an amplitude that decreases with the depth (Biot, 1962). Rayleigh waves are commonly used on practice. Similarly, analyzing Rayleigh waves velocity $V_{\mathrm{R}}$, it can be obtained a relationship between $V_{\mathrm{R}}, V_{\mathrm{S}}$, and the Poisson's ratio $v$ or between $V_{\mathrm{R}}, V_{\mathrm{S}}$ and $V_{\mathrm{P}}$ as follows:

$$
\left(\frac{V_{R}}{V_{S}}\right)^{6}-8\left(\frac{V_{R}}{V_{S}}\right)^{4}+8\left(\frac{V_{R}}{V_{S}}\right)^{2}\left[1+2\left(1-\frac{V_{S}{ }^{2}}{V_{P}{ }^{2}}\right)\right]-16\left(1-\frac{V_{S}{ }^{2}}{V_{P}{ }^{2}}\right)=0
$$

Details on this derivation can be obtained in Foti et al. (2014). When considering the seismic design of structures it has been studied the seismic bearing capacity (Tiznado and Paillao, 2014) and the seismic response of the soil that could induce amplification factors on the loads that affects the structure. Seismic response of soil deposits depends between other factors on the soil stratification that exist in a specific location. Shear wave velocity profiles have been used to predict the behaviour of a soil during an earthquake. Different site classification systems use a representative average of the shear wave velocity up to a depth of $30 \mathrm{~m}$ (Dobry et al., 2000). The depth is basically determined by the usual depth of borings and the cost of these. Obtaining this value allow us to categorize the soil in different classes that define different seismic response.

Seismic codes generally use $V_{\mathrm{S} 30}$ to characterize "site effects" and to select an appropriate response spectrum according to soil characteristics. The value of $V_{\mathrm{S} 30}$ is calculated using (2) as follows:

$$
V s_{30}=\frac{\sum_{i=1}^{n} h_{i}}{\sum_{i=1}^{n} \frac{h_{i}}{V s_{i}}}
$$

where $n$ is the number of layers up to $30 \mathrm{~m}$ depth and $h_{\mathrm{i}}$ and $V_{\mathrm{Si}}$ are the thickness and shear wave velocities of these layers, respectively. There are many other factors that have been found to be important in the seismic response that are not always considered, among them, the impedance ratio between surface and underlying deposits and the depth to bedrock.

Different in situ seismic techniques have been developed to determine shear wave velocity profiles. In Chile and in many parts of the world, it has become very popular the use of surface seismic methods such as MASW (Multichannel Analysis of Surface Waves). However, as the analysis of the disperse nature of surface waves is complicated, there are doubts whether the method is able to characterize a site up to $30 \mathrm{~m}$ depth measuring only from the surface. The MASW method consists in three main steps; (1) Data acquisition on the field, (2) Dispersion analysis of the data, and (3) Inversion to obtain $V_{\mathrm{S}}$ profile. This test can be performed using an active or passive source. The active source usually consists in a hammer blow or a heavy weight drop on the surface. The maximum depth of $V_{\mathrm{S}}$ that can be achieved using this method varies between 10 to $30 \mathrm{~m}$ depending on the site and the type of active source employed (Park et al., 1999). The maximum depth that reaches the method also depends of the spread length used by the geophones $D$, defined as the distance between the source and the further geophone, because this determines the maximum wavelength of the Rayleigh wave that can be measured (see Figure 1). In general, it is considered that $z_{\max } \leq D$. On the other hand, the minimum depth $z_{\min }$, is determined by the separation between geophones, $\mathrm{dx}$, as it is shown in Figure 1. It is considered that $z_{\text {min }} \geq 0.5 \lambda_{\text {min }}$ $=0.5 c_{\min } / f_{\max }$, where $c_{\text {min }}$ and $\lambda_{\text {min }}$ are phase velocity and wavelength, respectively, corresponding to a particular frequency $f_{\max }$. It is known that the receiver spacing affects the maximum wavenumber, which corresponds to the minimum wavelength (shallow layers). The minimum wavelength can be as low as the receiver spacing $\left(\lambda_{\min }=\right.$ $\mathrm{dx}$ ). Additional details of this method and the main factors that influence the measurements can be found in Park et al. (1999) and Foti et al. (2014).

Geophones with natural frequency of $4.5 \mathrm{~Hz}$ are used to measure the vertical component of the surface waves. The time of sampling is in the order of 1 to 2 seconds, the latter is used in the case of low shear wave velocities. The testing parameters typically advised for this type of measurements are shown in Table 1. These parameters would allow to measure depths $z_{\max }$ in the order of 20 to $30 \mathrm{~m}$. 


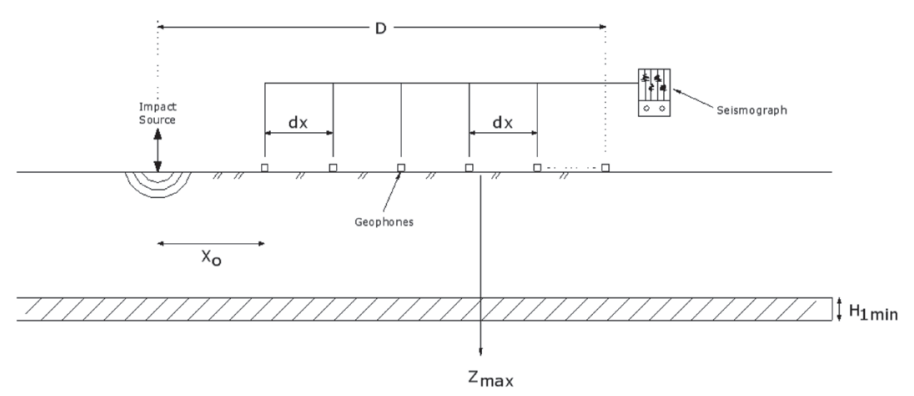

Figure 1: Scheme of MASW setup on the field

Table 1: Typical values for parameters setup in active MASW (Park et al., 2002)

\begin{tabular}{|l|c|}
\hline \multicolumn{1}{|c|}{ Parameter } & Typical value \\
\hline Source weight & $9.1 \mathrm{~kg}$ \\
\hline Receiver frequency & $4.5 \mathrm{~Hz}$ \\
\hline Source offset & $10 \mathrm{~m}$ \\
\hline Spread length & $50 \mathrm{~m}$ \\
\hline Receiver spacing & $2 \mathrm{~m}$ \\
\hline Recording time & $1 \mathrm{sec}$ \\
\hline Sampling rate & $1 \mathrm{~ms}$ \\
\hline
\end{tabular}

As it was mentioned previously, during the signal analysis there are two main processes that have to be performed: (1) Finding the dispersion curve, and (2) Inversion process.

The dispersion curve is found directly from the measurements of the geophones used on the field. In Figure 2 it is shown, as an example, the data for the Casablanca site after 5 blows in the ground. The dispersion curve is the most critical step to generate an adequate shear-wave velocity profile. In this work it has been applied a total of 5 blows in each site and the data has been stacked together to characterize a clear dispersion curve. From this figure, the representative curve that will be used in the next steps of the analysis is obtained. The analysis of this dispersion curve is obtained by using the software Geopsy.

Inversion of the curve obtained in the previous step is a mathematically complicated process. It is required the estimation of Poisson's ratio and density of the subsoil. It is an iterative process where a starting shear wave profile is established and the corresponding theoretical dispersion curve is deduced for that $V_{\mathrm{S}}$ profile. This is performed many times comparing the obtained dispersion curve with the measured curve on the field and using a least-squares approach to estimates how adequate is the $V_{\mathrm{s}}$ profiles adopted. In this form, it is deduced the $V_{\mathrm{S}}$ profile that generates the dispersion curve that is most similar to the measured curve on the field (through the assignation of a fitting error for each curve). More details of this process can be found in (Penumadu and Park, 2005).

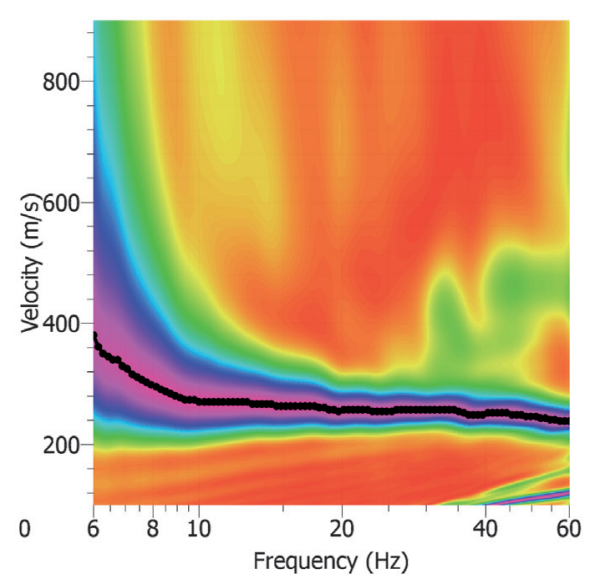

Figure 2: Dispersion curve using MASW in Casablanca site; stacking of five blows. Magenta indicates the maximum spectral amplitude.

In this work, results of shear wave velocities obtained from laboratory tests using bender elements are also used. Bender elements have been used since the late 1970s, for example Shirley (1978) and Shirley and Hampton (1978). These elements consist in a piezoceramic transmitter, which generates shear waves through the soil sample, and another piezoceramic that acts as a receiver and converts the shear movement in an electrical signal. The time from the shear wave to travel from the transmitter to the receiver is measured to calculate the shear wave velocity as the soil sample length is known. A detailed explanation for the use and interpretation of bender elements reading to deduce shear wave velocity is given in Lee and Santamarina (2005) and Leong et al. (2005).

The objective of this work is to compare $V_{\mathrm{S}}$ values obtained from MASW method and downhole tests in five sites. Shear waves velocity obtained from laboratory tests on undisturbed soil samples are also compared with the $V_{\mathrm{S}}$ profiles deduced from MASW.

\section{Experimental setup and procedure}

Sites were chosen as there were previous measurements of downhole testing performed in these locations. The 
locations form part of a Chilean network of seismometers that recorded the 2010 Chile earthquake (Saragoni et al., 2010). Stratigraphic information is also available at these site as boring were performed and will be shown for each location. MASW tests were performed using a Geode seismograph (from Geometrics), as shown in Figure 3a. This equipment has 24 channels of 24 bits each one with the main characteristics shown in Table 2.

Table 2: Main characteristics of the equipment used on the field

\begin{tabular}{|l|c|}
\hline \multicolumn{1}{|c|}{ Equipment setup } & Value \\
\hline $\begin{array}{l}\text { Frequency } \\
\text { measurements }\end{array}$ & $1.75 \mathrm{~Hz}$ to $20 \mathrm{kHz}$ \\
\hline Stacking precision & $1 / 32$ times the sampling interval \\
\hline Data storing & 16000 samples per channel \\
\hline Sampling intervals & 0.02 to $16 \mathrm{~ms}$ \\
\hline
\end{tabular}

The 12 geophones used corresponds to the model GS-11D/ PC-803 with a natural frequency of $4.5 \mathrm{~Hz}$, damping of $50 \%$, cut off frequency of $80 \mathrm{~Hz}$ and a sensibility of $0.7 \mathrm{~V} /$ $\mathrm{in} / \mathrm{sec}$. The active source used in this research, corresponds to the Standard Penetration Test SPT weight that is 63.5 $\mathrm{kg}$. This weight is released from an approximate height of $1.3 \mathrm{~m}$ as it is shown in Figure 3b. For measurements performed in Peñalolén, Maipú, Melipilla and Llolleo, it was used a source offset $\mathrm{X}_{0}$ of $8 \mathrm{~m}$, and geophone distance $\mathrm{dx}=5 \mathrm{~m}$. In Casablanca, due to space constrictions, the source offset was $10 \mathrm{~m}$ and the geophone distance $\mathrm{dx}=4$ $\mathrm{m}$. In all locations 5 blows were performed to obtain the dispersion curve of the site.
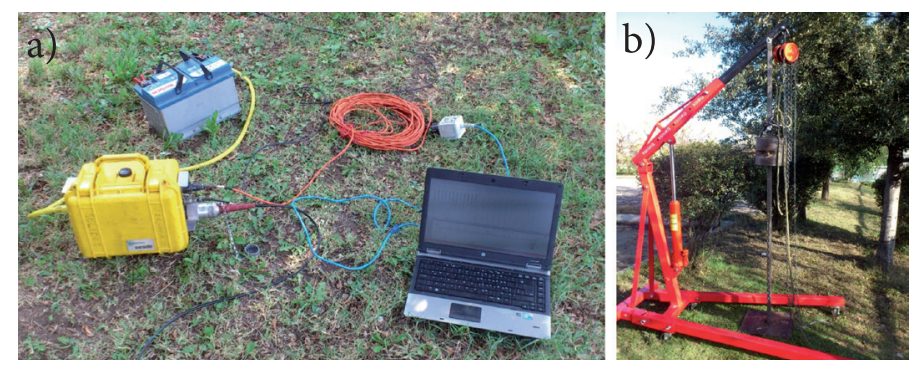

Figure 3: MASW field setup, a) seismograph, laptop and peripherals and b) impact load

Downhole tests were performed as part of the geotechnical study of the Chilean network of seismometers (Boroschek et al., 2012). Tests were performed taking measurements every $2 \mathrm{~m}$ of depth, and using a three directional geophone. Downhole results are analyzed according to the interval method (Kim et al., 2004). In Llolleo, there is a downhole test published nearby reported by Verdugo (2009). Additional details on how the downhole tests are performed can be found in ASTM (2014).

\section{Test results}

In total, $25 \mathrm{MASW}$ tests were performed during this study, these are complemented by the analysis of 5 downhole tests and the stratigraphy found in each boring performed previously. All MASW tests were carried out as close as possible to the location of the boring. Shear wave velocity profiles were deduced directly from the downhole tests and through the MASW equipment. Differences in the $V_{\mathrm{S}}$ profile for each site are analyzed in terms of the stratigraphic profile and the values of $V_{\mathrm{S} 30}$ deduced. The results obtained by the surface methods are compared with downhole tests. Additionally, results are complemented by existing bender elements tests on soil samples obtained from the field (Boroschek et al., 2012). Tests are performed on reconstituted specimen or undisturbed samples depending on the type of soil/rock tested. More information about obtaining shear wave velocities from bender elements can be found in Lee and Santamarina (2005) among others.

\section{Stratigraphy}

The stratigraphy for each location was informed by the University of Chile (Boroschek et al., 2012). Stratigraphy is performed based on observations of samples obtained from drilling to depths larger than $30 \mathrm{~m}$, but informed here only up to $30 \mathrm{~m}$ that is the interest zone for estimating $V_{\mathrm{s}}$. In Figures 4 to 6 the different stratigraphy of each site is shown.

\section{Downhole testing}

Downhole tests were performed every $2 \mathrm{~m}$ in each site. An example of waveforms obtained at Melipilla site is shown in Figure 7. Using these waveforms two independent interpretations of the arrival time for shear waves were performed in each site. This generates two $V_{\mathrm{s}}$ profiles up to $30 \mathrm{~m}$ that have user depending variability. 


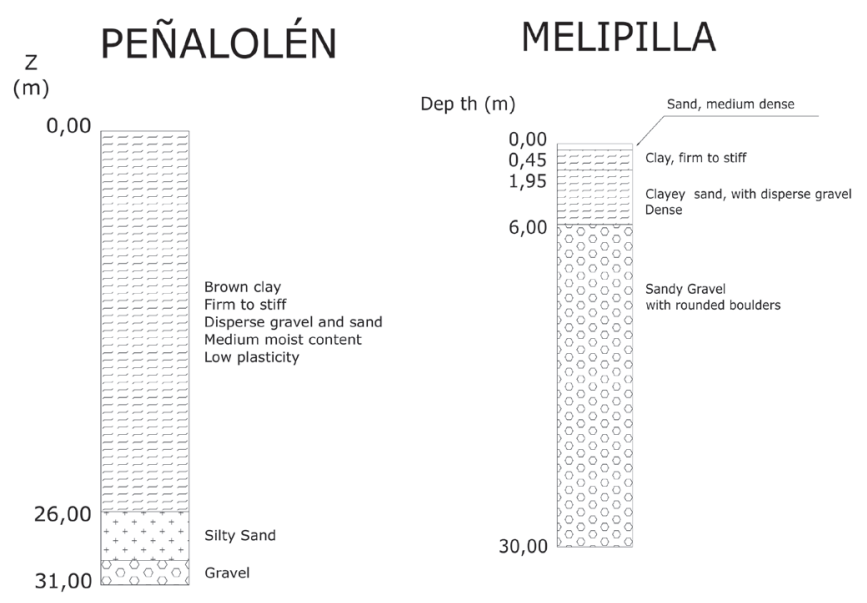

Figure 4: Soil stratigraphy of Peñalolen and Melipilla
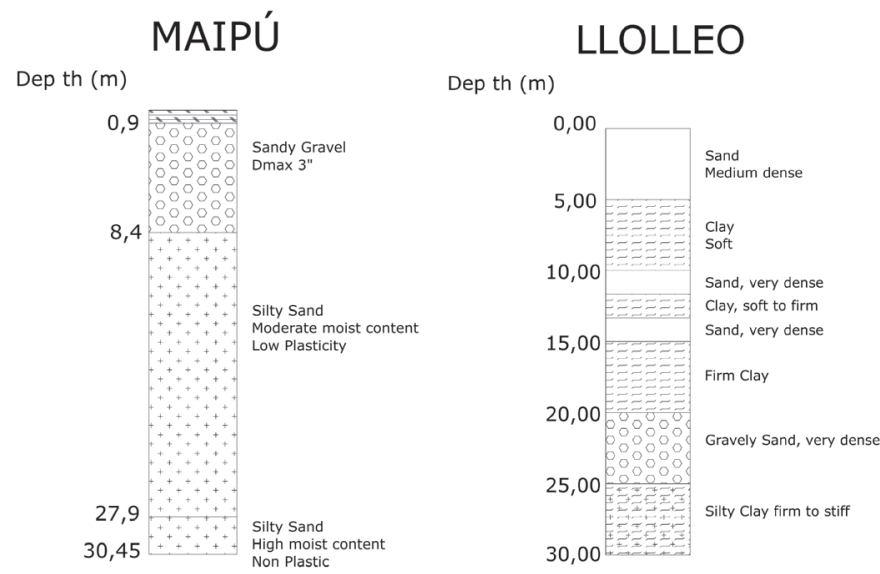

Figure 5: Soil stratigraphy of Maipú and Llolleo

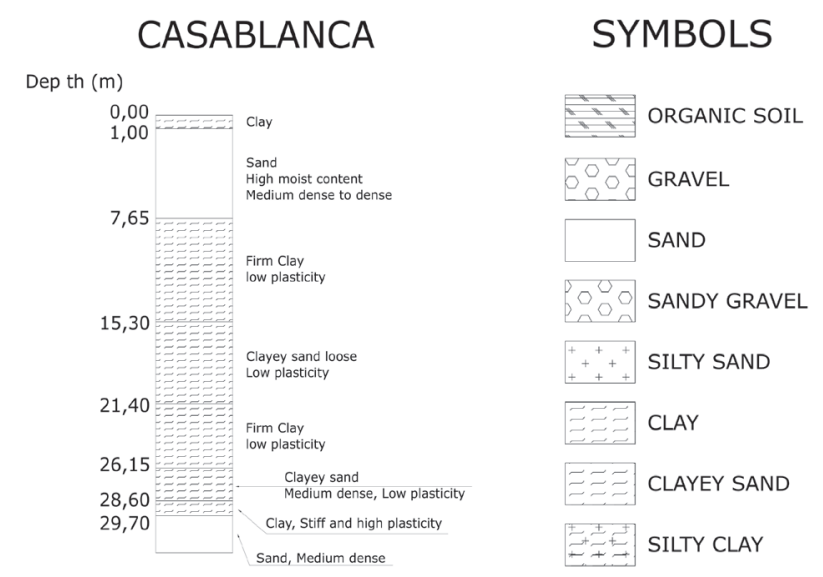

Figure 6: Soil stratigraphy of Casablanca and symbols

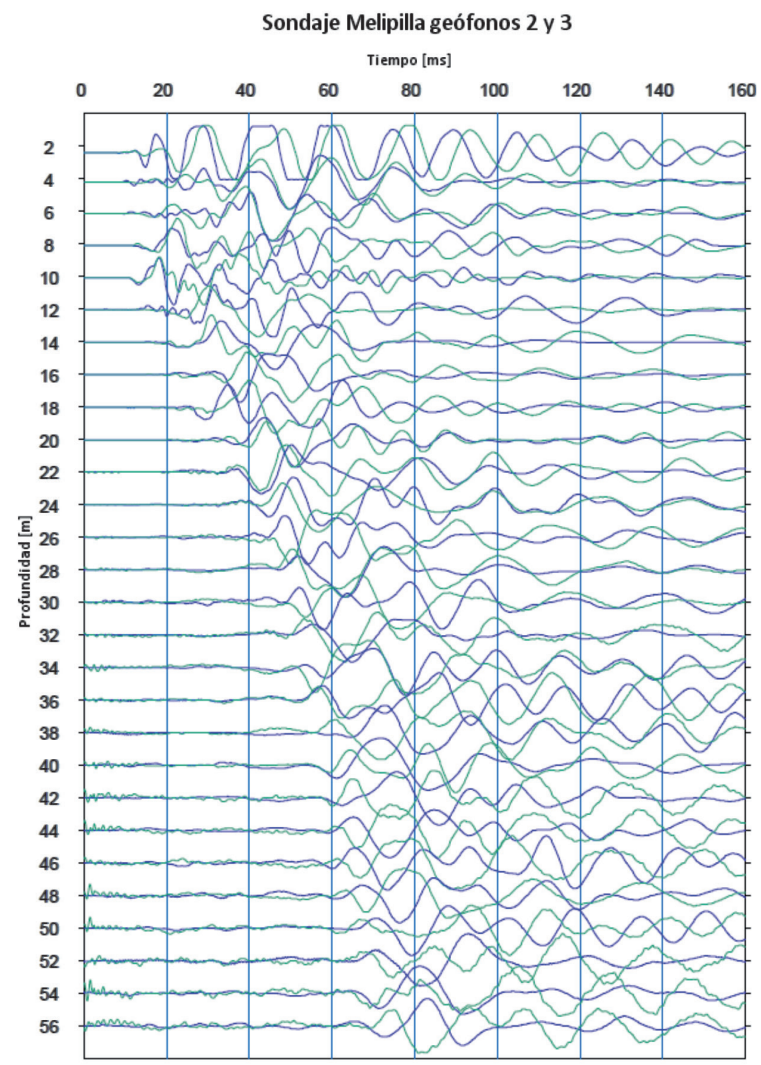

Figure 7: Waveforms from a downhole test at Melipilla (Boroschek et al., 2012)

\section{Field shear wave measurements}

$V_{\mathrm{S}}$ profiles obtained from MASW tests at each site are shown in this paper. Dispersion curves are first shown and it is estimated the maximum depth that it is advisable to consider in each case based on the dispersion curve obtained. Then it is shown the $V_{\mathrm{s}}$ profile obtained by using MASW data with the Geopsy software and the downhole deduction of $V_{\mathrm{S}}$ by two different users. Also, when available, $V_{\mathrm{S}}$ obtained from undisturbed or reconstituted (at the same density) specimens, are shown. These tests are performed in a triaxial cell under similar effective stress that has the soil at the corresponding depth in the field.

\section{Maipú site}

In Figure 8, it is shown the dispersion curve obtained after 5 blows on the field. In Figure 9, it is shown the dispersion curves adopted for each software. Finally, Figure 10 shows the estimate of $V_{\mathrm{S}}$ profiles for MASW, downhole tests and one soil specimen reconstituted and tested with bender elements under a similar confining pressure as it is expected on the field. All the deduced profiles are very 
similar to each other. The larger difference is observed between 2 and $8 \mathrm{~m}$ deep where the downhole test gives a higher estimation of shear wave velocity. In this zone there is a dense sandy-gravel that is not detected in detail by the MASW analysis.

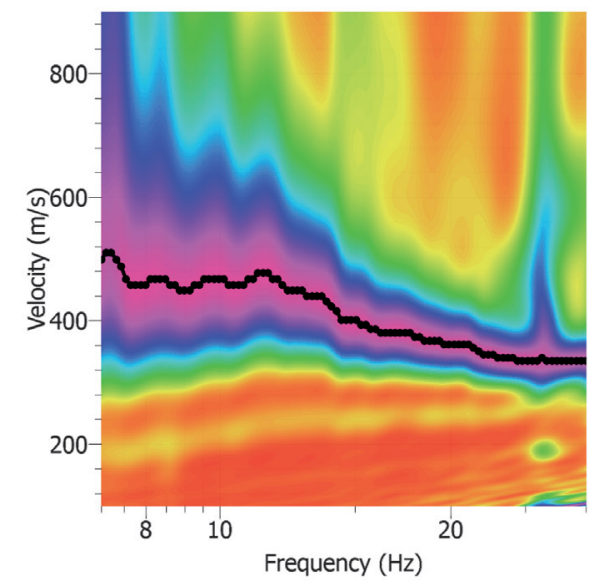

Figure 8: Dispersion curve obtained at Maipú site; stacking of two blows

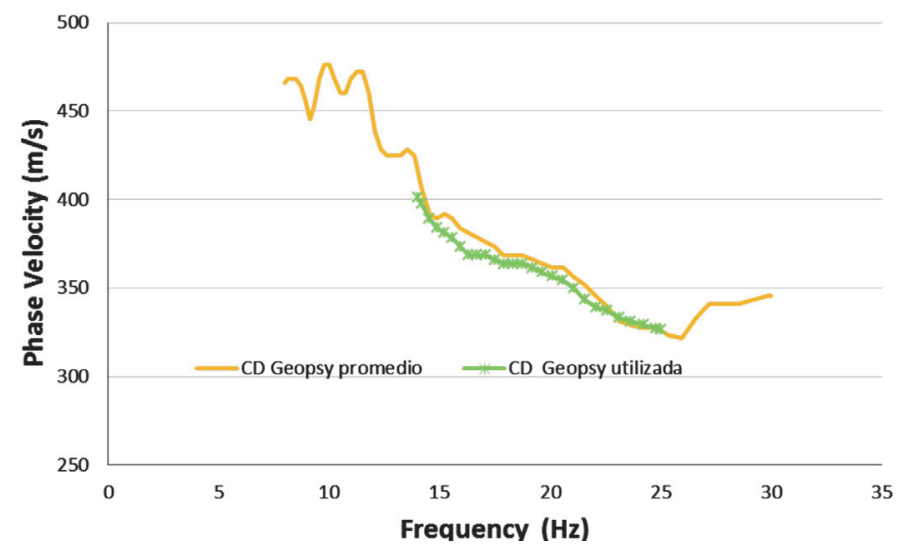

Figure 9: Dispersion curve used at Maipú site

On the other hand, the deduced shear wave velocity using bender elements in the reconstituted sample (reconstituted to the same density observed on the field) is lower, about $65 \%$ of the $V_{\mathrm{S}}$ obtained by MASW and downhole tests. This is believed to be due to the loss of structure, cementation or aging effect due to sample reconstitution.

Considering expressions (2) and (3) (Park et al., 1999), it can be deduced the maximum depth and minimum definable thickness of the shallower layer, according to the frequencies and velocities derived from the dispersion curve (first mode of vibration). According to Stokoe et al. (1994):

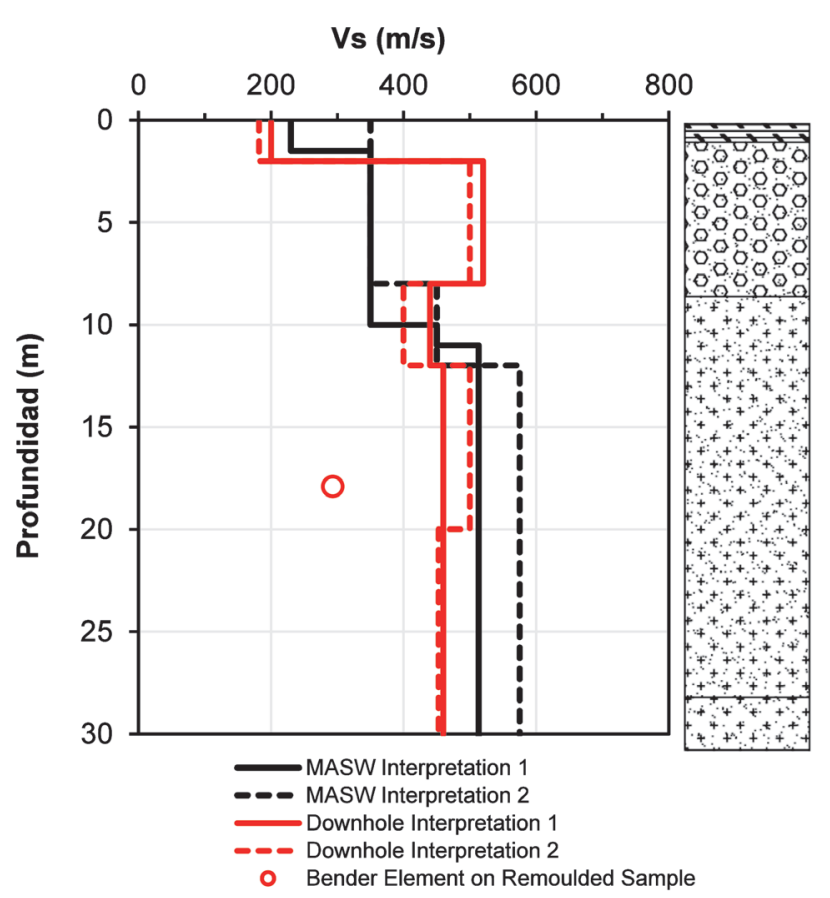

Figure 10: $V_{\mathrm{S}}$ profiles at Maipú site

$$
H_{\min } \geq 0.5 \lambda_{\min }=0.5 \frac{c_{\min }}{f_{\max }}
$$

where $H_{\text {min }}$ is the minimum definable thickness of the shallower layer, $\lambda_{\min }$ and $c_{\min }$ are wavelength and phase velocity corresponding to a $f_{\max }$. According to Rix and Leipski (1991):

$$
z_{\max }=\frac{c_{1}}{2 f_{1}}
$$

where $c_{1}$ is the phase velocity for the frequency $f_{1}$. For the Maipú site these values are: $z_{\max }=29.4 \mathrm{~m}$ and $H_{\text {min }}=5.3 \mathrm{~m}$. Therefore, it can be confirmed from the measurements performed and the dispersion curves obtained from those measurements that it is possible to obtain the $V_{\mathrm{s}}$ profile up to approximately $30 \mathrm{~m}$ deep and the best "resolution" of these measurements are in layers of $5.3 \mathrm{~m}$.

\section{Peñalolen}

Similarly, at Peñalolen site it was derived the shear wave velocity from MASW (see Figure 11), downhole, and bender elements tests were performed in undisturbed soil obtained from that depth. The result of a bender elements test, considering the expected effective stress on the field, of an undisturbed sample, gives a very close value of $V_{\mathrm{S}}$ (related to downhole and MASW) at the same depth where 
the soil sample was extracted. $V_{\mathrm{S}}$ results from downhole and MASW tests are very close up to $30 \mathrm{~m}$.

It is important to mention that according to the dispersion curve estimated it is possible to consider the maximum depth for using MASW tests equal to $17.9 \mathrm{~m}$ and a minimum thickness of $3.6 \mathrm{~m}$. However, the method compares well with downhole tests from 20 to $30 \mathrm{~m}$, it could be due to the small change in $V_{\mathrm{S}}$ existing at those depths (see Figure 12).

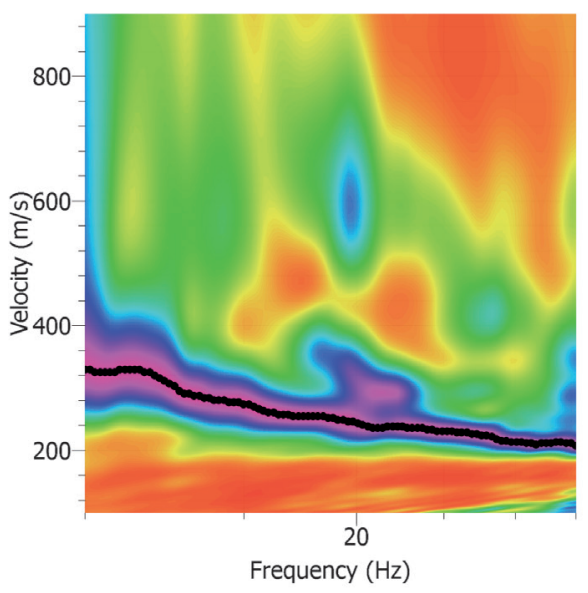

Figure 11: Dispersion curve for Peñalolén site; stacking of four blows

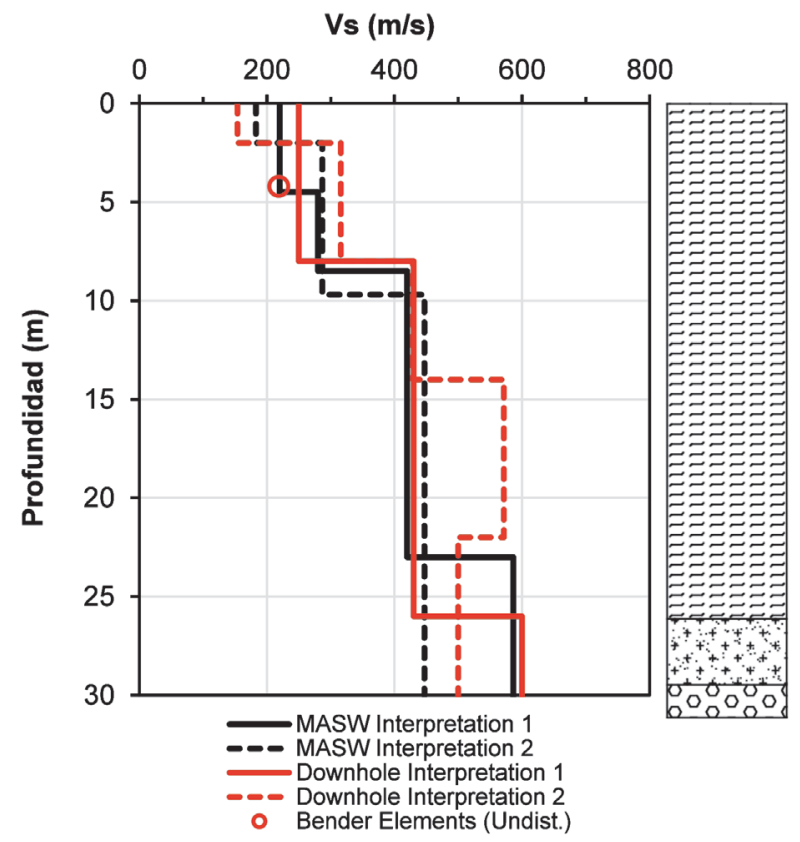

Figure 12: $V_{S}$ profiles deduced at Peñalolén site

\section{Casablanca}

In this site the dispersion curve obtained from the 5 blows on the field is shown in Figure 13. The dispersion curve obtained is clear in a wide range of frequencies this allows us to estimate the $V_{\mathrm{s}}$ profile up to depths of $37.9 \mathrm{~m}$ in this case and minimum thickness of $2.4 \mathrm{~m}$.

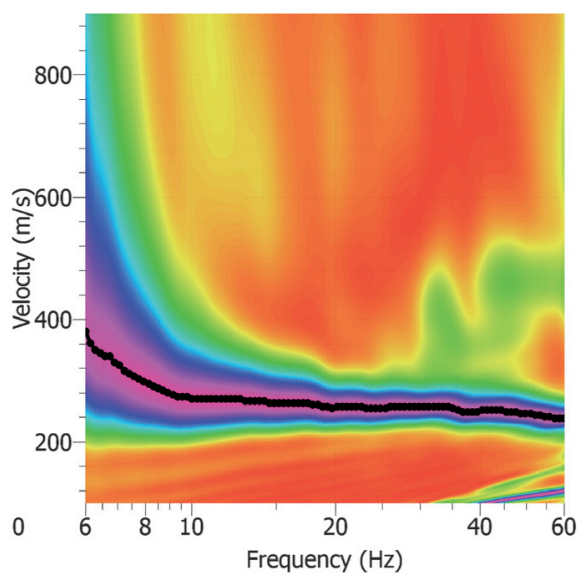

Figure 13: Dispersion curve for Casablanca site; stacking of five blows

The shear wave velocity profiles are very similar up to approximately $22 \mathrm{~m}$ where some dispersion starts to be observed between MASW and downhole methods. Shear wave velocity $V_{\mathrm{S}}$, deduced on undisturbed samples gives a very close value to the measured on downhole tests at 22 $m$ deep where firm clay was observed on the borings on the field. A lower value than deduced from the field values is obtained on bender elements tests where the soil was observed to pass from firm clay to medium dense sand (see Figure 14).

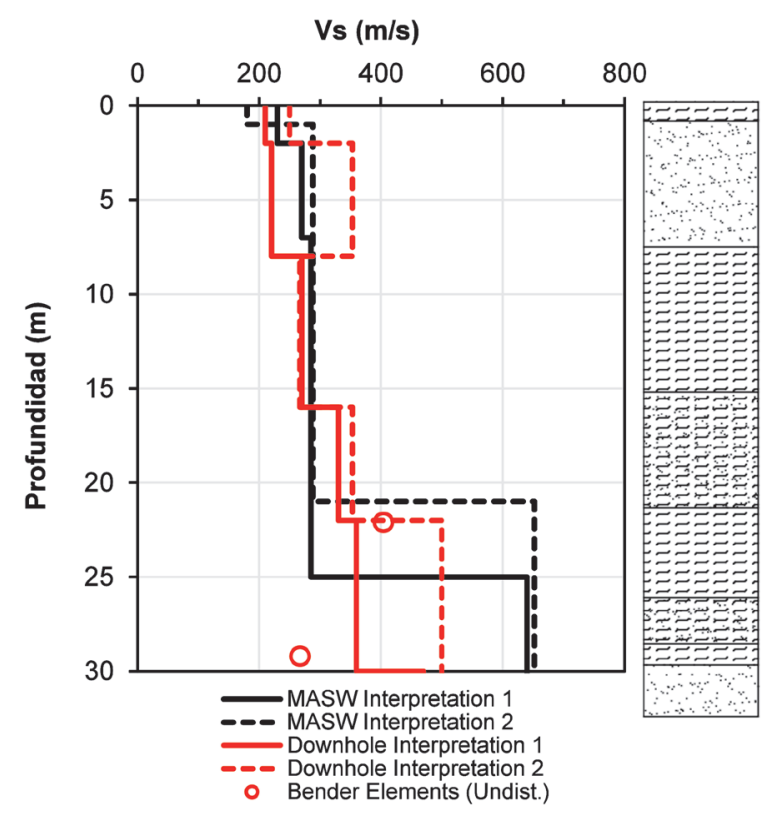

Figure 14: $V_{\mathrm{S}}$ profiles obtained at Casablanca site 


\section{Melipilla}

In this site, there is a considerable change of soil type and rigidity at $6 \mathrm{~m}$. Up to $6 \mathrm{~m}$ it can be found layers of sandy clay and clay, then below those layers it is found gravels with boulders up to 6 inches in diameter. This creates a large impedance of the soil that makes difficult to interpret the tests results in both cases downhole and MASW. Bender elements tests were performed on reconstituted specimens at depths lower than $5 \mathrm{~m}$ and in an undisturbed rock sample at $60 \mathrm{~m}$ depth. Bender elements results are very close to MASW deduction of $V_{\mathrm{S}}$ for depths lower than $5 \mathrm{~m}$. Also there is a good agreement of $V_{\mathrm{S}}$ between MASW and bender elements tests on a rock sample at depths of $60 \mathrm{~m}\left(V_{\mathrm{S}}=1200\right.$ $\mathrm{m} / \mathrm{s}$ ) although according to the dispersion curve deduced from MASW, the maximum depth up to $V_{\mathrm{S}}$ that can be obtained is of $25.4 \mathrm{~m}$ with a minimum thickness of $2.4 \mathrm{~m}$.

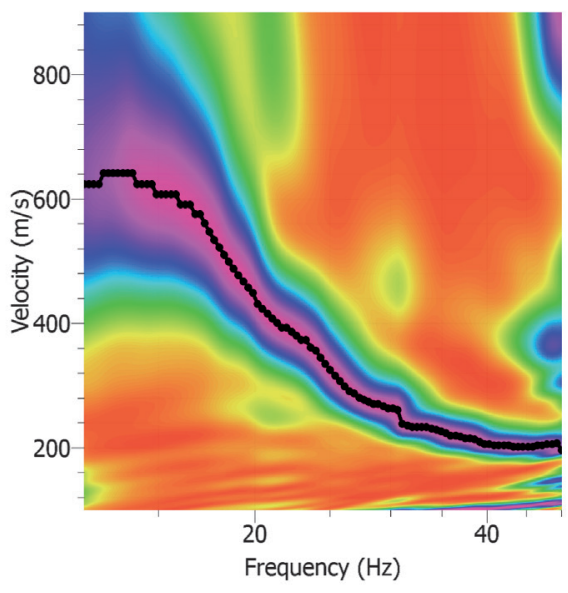

Figure 15: Dispersion curve obtained at Melipilla site; stacking of four blows

MASW $V_{\mathrm{S}}$ profile using Geopsy shows a sudden increase at about $4.5 \mathrm{~m}$. Downhole methods seem to give an average value of $V_{\mathrm{S}}$ from 5 to $30 \mathrm{~m}$. The $V_{\mathrm{S}}$ values obtained with MASW for depths shallower than $5 \mathrm{~m}$ seems to correlate relatively well with bender elements (see Figure 16).

\section{Llolleo}

Near this site, there is a downhole test performed and informed in Verdugo (2009). Figure 17 shows the MASW profiles obtained during this research. It is possible to observe in Figure 18 a very good agreement on $V_{\mathrm{S}}$ values up to $13 \mathrm{~m}$, below that depth there is a considerable difference in the $V_{\mathrm{s}}$ profiles obtained.

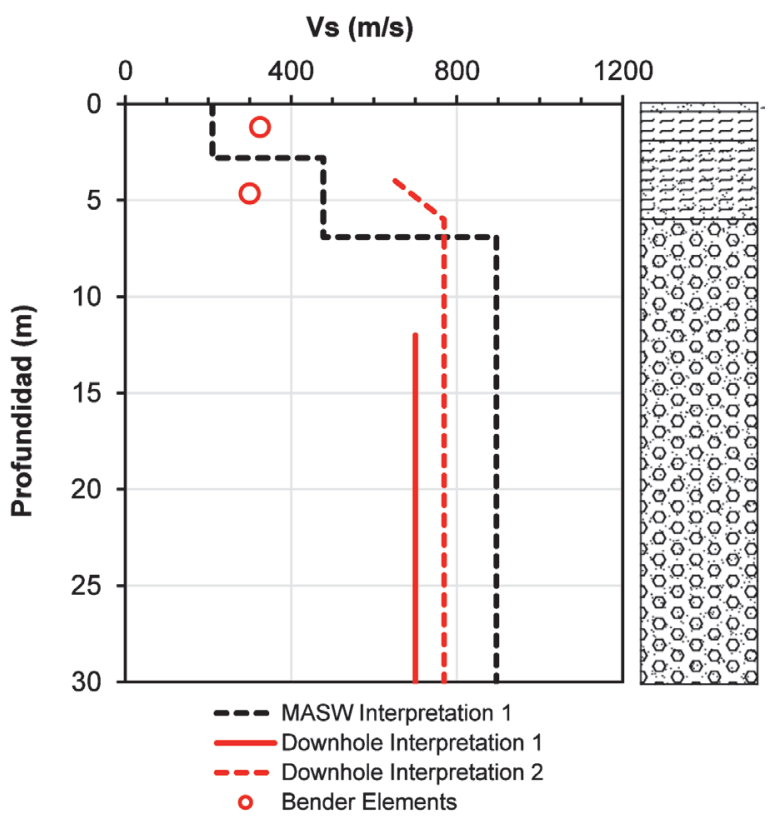

Figure 16: $V_{\mathrm{S}}$ profiles obtained at Melipilla site

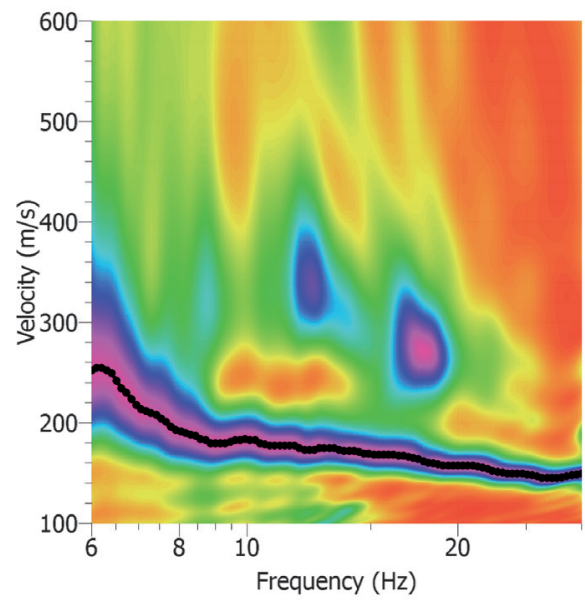

Figure 17: Dispersion curve obtained at LLolleo site; stacking of three blows

According to the field measurements using active MASW, it is possible to deduce that the maximum depth where the $V_{\mathrm{S}}$ can be obtained is of $41 \mathrm{~m}$ and that the minimum thickness that can be determined is equal to $3.2 \mathrm{~m}$. From Figure 18 it is clear that the MASW method was not able to capture adequately the dense sandy-gravel layer existing between the 20 and $25 \mathrm{~m}$ deep. However, calculated values of $V_{\mathrm{S} 30}$ are equal to 266 and $264 \mathrm{~m} / \mathrm{s}$ for MASW and 227 $\mathrm{m} / \mathrm{s}$ for downhole test (difference of about 17\%). This change in $V_{\mathrm{S} 30}$ values does not change the soil type in most classification systems (Dobry et al., 2000). 


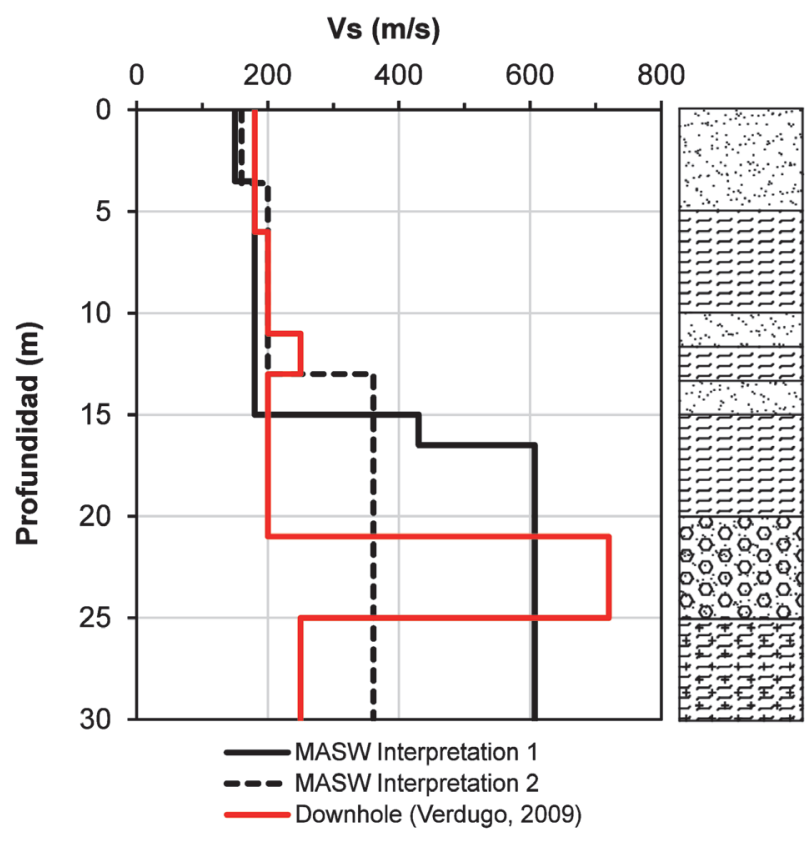

Figure 18: $V_{\mathrm{S}}$ profiles obtained at Llolleo site

\section{Conclusions}

Different methods to determine the shear wave velocity in soils are compared in this paper. Even though measurements and analysis are very different, the results tend to be close between each other. If the objective of determination of the $V_{\mathrm{S}}$ profile, is the seismic classification through the use of $V_{\mathrm{S} 30}$, MASW and downhole tests give very similar results and no change on soil classification is expected unless the $V_{\mathrm{S} 30}$ value is close to the limits for a specific seismic soil type. The measurement of shear wave velocities on undisturbed soil samples shows to be an adequate technique to confirm $V_{\mathrm{S}}$ values in a particular soil depth. This confirms the robustness of the employed methods in this work and in the professional practice.

The main conclusions that are drawn from this study are the following:

- Deduction of shear wave velocity $V_{\mathrm{S}}$ profiles performed using downhole and active MASW tests are very similar except in cases where there is an intermediate dense sandy-gravel layer that is not captured by MASW analysis, as in the case of Maipú and Lloleo sites.

- Shear velocities deduced from bender elements tests on undisturbed samples are very close to the shear velocities obtained from downhole and MASW tests.
- Shear velocities deduced from bender elements tests on remolded soil samples show a large difference with the values obtained from downhole and MASW tests. This is due to the loss of fabric or cementation of the soil sample.

- In general, the maximum depth that is possible to reach, using the active MASW with a weight of 63.5 $\mathrm{kg}$ that drops from $1.3 \mathrm{~m}$, was found to be between 17.9 to $37.9 \mathrm{~m}$. Data after this maximum depth has to be considered with precaution.

- The minimum shallower thickness that can be detected using active MASW was found to be in the range between 2.4 and $5.3 \mathrm{~m}$. These are considered appropriate for most geotechnical projects.

\section{References}

ASTM (2014). Standard test methods for downhole seismic testing, ASTM D7400. West Conshohocken, PA., USA

Biot, M.A. (1962). Mechanics of deformation and acoustic propagation in porous media. Journal of Applied Physics 33(4), $1482-1498$

Boroschek, R.L., Yañez, F., Bejarano, I., Molnar, S. and Torres, A. (2012). Geotechnical characterization University of Chile strong motion accelerograph stations. University of Chile

Dobry, R., Borcherdt, R.D., Crouse, C.B., Idriss, I.M., Joyner, W.B., Martin, G.R., Power, M.S., Rinne, E.E. and Seed, R.B. (2000). New site coefficients and site classification system used in recent building seismic code provisions. Earthquake Spectra 16(1), $41-67$

Everett, M.E. (2013). Near-surface applied geophysics. Cambridge University Press

Foti, S., Lai, C.G., Rix, G.J. and Strobbia, C. (2014). Surface wave methods for near-surface site characterization. CRC Press Kim, D.S., Bang, E.S. and Kim, W.C. (2004). Evaluation of various downhole data reduction methods for obtaining reliable $\mathrm{V}_{\mathrm{s}}$ profiles. Geotechnical Testing Journal 27(6), 1 - 13

Lee, J.S. and Santamarina, J.C. (2005). Bender elements: Performance and signal interpretation. Journal of Geotechnical and Geoenvironmental Engineering 131(9), 1063 - 1070 
Leong, E.C., Rahardjo, H., and Yeo, S.H. (2005). Measuring shear wave velocity using bender elements. Geotechnical Testing Journal 28(5), 1 - 11

Nazarian, S. and Stokoe, K.H. (1986). Use of surface waves in pavement evaluation. Transportation Research Record 1070, $132-144$

Park, C.B., Miller, R.D. and Miura, H. (2002). Optimum field parameters of an MASW survey. Proceedings of the Society of Exploration Geophysicists, Japan, Tokyo, 22 - 23

Park, C.B., Miller, R.D. and Xia, J. (1999). Multichannel analysis of surface waves. Geophysics 64(3), 800 - 808

Penumadu, D. and Park, C.B. (2005). Multichannel analysis of surface wave (MASW) method for geotechnical site characterization. Proceedings of the Geo-Frontiers Conference, Austin, Texas

Rix, G. J., and Leipski, E.A. (1991). Accuracy and resolution of surface wave inversion: Recent advances in instrumentation, data acquisition and testing in soil dynamics. Geotechnical Special Publication no. 29, American Society of Civil Engineers, 17 - 23
Saragoni, G.R., Lew, M., Naeim, F., Carpenter, L.D., Youssef, N.F., Rojas, F. and Adaros, M.S. (2010). Accelerographic measurements of the 27 February 2010 offshore Maule, Chile earthquake. The Structural Design of Tall and Special Buildings 19(8), $866-875$

Shirley, D.J. (1978). An improved shear wave transducer. The Journal of the Acoustical Society of America 63(5), 1643 - 1645

Shirley, D.J. and Hampton, L.D. (1978). Shear-wave measurements in laboratory sediments. The Journal of the Acoustical Society of America 63(2), 607 - 613

Stokoe, K.H., Wright, S.G., Bay, J.A. and Roesset, J.M. (1994). Characterization of geotechnical sites by SASW method. Geophysical Characterization of Sites, IBH Oxford Press, New Delhi, India, 15 - 25

Tiznado, J.C. and Paillao, D. (2014). Analysis of the seismic bearing capacity of shallow foundations. Revista de la Construcción 13(2), 40 - 48

Verdugo, R. (2009). Amplification phenomena observed in downhole array records generated on a subductive environment. Physics of the Earth and Planetary Interiors 175(1), 63 - 77 